\title{
POLÍTICAS E DINÂMICA RECENTES DA INDÚSTRIA PETROLÍFERA NO ESTADO DO RIO DE JANEIRO
}

\author{
Leandro Bruno Santos ${ }^{1}$ \\ ORCID: https://orcid.org/0000-0001-9163-8568 \\ Marta Lucia Azevedo Ferreira ${ }^{2}$ \\ ORCID: http://orcid.org/0000-0002-5998-5452
}

Heitor Soares Mendes ${ }^{3}$

ORCID:https://orcid.org/0000-0002-5134-6752

Recebidoem: 14/04/2021

Publicado em: 30/06/2021

\section{RESUMO}

Este artigo tem por objetivo contribuir para a reflexão e composição de uma agenda de políticas públicas para o desenvolvimento econômico do Estado do Rio de Janeiro (ERJ) a partir da indústria petrolífera que nele tem papel de destaque. Trata-se de uma pesquisa aplicada e descritiva baseada na utilização de técnicas de documentação indireta como a pesquisa bibliográfica e documental. Verificou-se que a atração de investimentos para o estado tendo em vista o aumento dos níveis de produção, emprego e renda apresentou resultados limitados. Parte expressiva dos subsídios fiscais oferecidos se concentraram em poucas empresas petrolíferas com destaque para a Petrobras, tanto no segmento de exploração e produção que é predominante no estado, como de distribuição de derivados. As informações obtidas ratificam o padrão de especialização da economia fluminense em recursos naturais apontado em estudos anteriores, mas apesar dos efeitos positivos em termos de emprego e renda, as atividades de exploração e produção não são capazes de levar ao desenvolvimento regional por si mesmas, posto que geram poucos encadeamentos a montante por serem intensivas em capital. É fundamental a retomada de políticas nacionais para a indústria petrolífera voltadas para a melhoria das condições de infraestrutura, o fortalecimento da indústria nacional de fornecedores de bens e serviços, a formação de recursos humanos em diversos níveis e a geração e transferência de conhecimentos científicotecnológicos de fronteira. No entanto, a articulação entre políticas nacionais e regionais é essencial, de modo a estimular o comportamento cooperativo dos agentes econômicos em uma perspectiva de longo prazo.

PALAVRAS-CHAVE: Políticas Públicas; Desenvolvimento econômico; Desenvolvimento regional; Indústria Petrolífera; Estado do Rio de Janeiro.

\footnotetext{
${ }^{1}$ Professor da Universidade Federal Fluminense (UFF) / Campos dos Goytacazes vinculado ao Departamento de Geografia de Campos (GRC) e ao Programa de Pós-Graduação em Geografia (PPG).

${ }^{2}$ Professora do Centro Federal de Educação Tecnológica Celso Suckow da Fonseca (CEFET/RJ) vinculada ao Departamento de Ensino Médio e Técnico e ao Programa de Pós-Graduação em Desenvolvimento Regional e Sistemas Produtivos (PPDSP).

${ }^{3}$ Professor do Centro Federal de Educação Tecnológica Celso Suckow da Fonseca (CEFET/RJ) vinculado ao Departamento de Ensino Médio e Técnico.
} 


\title{
POLICIES AND RECENT DYNAMICS OF LA INDUSTRIA PETROLERA IN THE STATE OF RÍO DE JANEIRO
}

\begin{abstract}
This paper contributes to the reflection and composition of a public policy agenda for the socioeconomic development of the state of Rio de Janeiro from the oil industry that has a prominent role in it. It is an applied and descriptive research based on the use of indirect documentation techniques such as bibliographic and documentary research. Itwas found that the attraction of investments to the state with a view to increasing levels of production, employment and income showed limited results. A significant part of the tax subsidies offered were concentrated in a few oil companies, with emphasis on Petrobras, both in the exploration and production segment that is predominant in the state, and in the distribution of oil products. The findings confirm the pattern of specialization of the state's economy in natural recources pointed out in previous studies, but in spite of the positive effects in terms of employment and income, exploration and production activities are not capable of leading to regional development on their own, given that generate few upstream chains because they are capital intensive. It is essential to resume national policies for the oil industry aimed at improving infrastructure conditions, strengthening the national industry of suppliers of goods and services, training human resources at various levels and generating and transferring cutting-edge scientific and technological knowledge. However, the articulation between national and regional policies is essential, in order to stimulate the cooperative behavior of economic agents from a long-term perspective.
\end{abstract}

KEYWORDS: Public Policies; Economic development; Regional development; Oil and gas industry; State of Rio de Janeiro.

\section{INTRODUÇÃO}

As cadeias produtivas se encontram no centro do debate sobre o desenvolvimento regional ao impulsionarem as principais atividades econômicaspor meio das externalidades positivas geradas (MADUREIRA, 2015). Elas representam um conjunto de etapas consecutivas pelas quais passam e vão sendo transformados e transferidos diversos tipos de insumos (DANTAS; KERSTENETZKY; PROCHNIK, 2013). Contudo, para serem capazes de gerar o crescimento e o desenvolvimento econômico regional, elas dependem da ação indutora do Estado por intermédio de políticas públicas (LIMA; SIMÕES, 2010).

Como destaca Amaral Filho (2001), o desenvolvimento regional é um processo contínuo de ampliação, tanto da capacidade de agregação de valor sobre a produção gerada na região, como da capacidade de absorção da região pela retenção do excedente econômico nela gerado ou ainda pela capacidade de atração de excedentes econômicos oriundos de outras regiões. Esse processo tem como principal resultado o aumento dos níveis de produção, emprego e renda conforme o modelo de desenvolvimento regional estabelecido. 
Em contraposição às críticas a essa abordagem por negligenciar as relações entre as dimensões regional e nacional, o autor destaca que o jogo entre os atores envolve regras comuns como a política macroeconômica e o sistema político-administrativo. Por isso é preciso levar em conta a combinação entre o comportamento cooperativo dos atores regionais - sejam indivíduos, organizações ou empresas - em relação ao todo nacional, de modo a evitar que a melhoria da qualidade de vida em determinada região possa ocorrer em detrimento de outras.

Como lembra Ferreira (2015), os anos 1990no país foram marcadospor grandes mudanças em decorrência do processo de reestruturação econômica e da abertura da economia. Mas a autossuficiência do petróleo declarada em 2006 e a descoberta de reservas na camada pré-sal anunciadas em 2007 alçaram a indústria petrolífera brasileira a um novopatamar por ensejar amplas oportunidades econômicas. Desde então, ela vem sendo alvo de políticas de caráter nacional e regional, destacando-se neste artigo estas últimas.

A partir das considerações anteriores, este artigo se propõe a contribuir para a reflexão e composição de uma agenda de políticas públicas para o desenvolvimento econômico do Estado do Rio de Janeiro (ERJ) a partir da indústria petrolífera que nele tem papel de destaque. Como assinalam Ferreira (2015), Oliveira e Melo (2015), Britto, Cassiolato e Marcellino (2015) e Mendes, Ferreira e Cavalieri (2017), o estado foi protagonista da indústria petrolífera no século $\mathrm{XX}$, mantendo-se como tal no século XXI, em que pese o cenário menos favorável imposto pela queda do preço do petróleo desde 2014.

A riqueza de recursos agrícolas e minerais como petróleo e gás natural e sua contribuição para o desenvolvimento econômico de países e regiões é um tema antigona Ciência Econômica envolvendo uma vasta, complexa e controversa literatura. Partindo da visão inicial e intuitiva de que tais recursos constituemuma bênção, teóricos de diferentes vertentes vêm contribuindo para o aprofundamento do tema considerando que esses recursos representam uma maldição e sob determinadas condições uma oportunidade.

Como ilustram Veríssimo (2019) eLumbreras e Piquet (2020), é no contexto desse atual e oportuno debate que se insere a contribuição do presente artigo. Ele se divide em cinco seções além dessa introdução. Na seção dois é apresentada uma revisão da literatura sobre a relação entre abundância de recursos naturais e desenvolvimento econômico e na seção três a metodologia adotada. Na seção quatro é oferecida uma breve caracterização da indústria petrolífera e das políticas nacionais com ênfase naquelas voltadas para o ERJ.Em seguida, a dinâmica da indústria petrolífera é analisada a partir dos resultados obtidos. $\mathrm{Na}$ seção seis são apresentadas as considerações finais e, em seguida, as referências utilizadas. 


\section{PETRÓleO, GÁS NATURAL E DESENVOLVIMENTO ECONÔMICO}

Desde a $2^{\text {a }}$ Guerra Mundial, o petróleo vem estimulando a competição entre empresas e países pelo acesso a reservas e pela exploração e produção em novas fronteiras marítimas (YERGIN, 2010). A dimensão geopolítica é constitutiva e distintiva da indústria petrolífera que tem alto potencial de atração de investimentos e de contribuição para o desenvolvimento econômico dos países. Contudo, a transformação dessa riqueza natural em riqueza material e melhoria da qualidade de vida das populações não é um processo trivial, especialmente para os países menos desenvolvidos (CAVALIERI; HASENCLEVER, 2019; LUMBRERAS; PIQUET, 2020)

Embora a associação entre abundância de recursos naturais e efeitos econômicos positivos remonte às contribuições pioneiras da Ciência Econômica com base na teoria das vantagens comparativas, essa associação passou a ser debatidapor acadêmicos canadenses nos anos 20, 30 e 40 do século XX com otimismo e pelos teóricos do desenvolvimento nas décadas de 50, 60 e 70 com viés crítico, razão pela qual estes últimos são considerados precursores da literatura que aborda a maldição dos recursos naturais (DI JOHN, 2011; MACIEL, 2015).

Como mostram os autores, a visão prevalente no início do século $\mathrm{XX}$ de recursos naturais como propulsores do desenvolvimento econômico era baseada no argumento de que recursos agrícolas e minerais abundantes como petróleo e gás natural não requerem processos produtivos sofisticados e são orientados pela demanda externa, daí o foco na exportação. Acreditava-se ainda que os benefícios dos setores produtivos envolvidos seriam disseminados para outros setores gerando resultados positivos para a toda a economia.

Os autores mostram ainda que a visão de recursos naturais como empecilhos ao desenvolvimento econômico surgiu nas décadas seguintes a partir dos teóricos vinculados à Comissão Econômica para a América Latina e o Caribe (Cepal) fundada em 1948. Eles distinguem as especificidades dos países desenvolvidos que ocupam o centro do sistema capitalista e aqueles subdesenvolvidos da periferia que convivem com três tendências persistentes:a deterioração dos termos de troca no longo prazo decorrente da alta volatilidade dos preços dos bens primários, a heterogeneidade estrutural e o desequilíbrio externo.

De fato, a deterioração dos termos de troca dos países produtores de bens primários apresentada por Prebisch (1949) e Singer (1950) é central na interpretação histórico-estrutural cepalina. Enquanto os países desenvolvidos são consumidores de bens primários e produtores 
de bens industriais, os subdesenvolvidos são consumidores de bens industriais e produtores de bens primários, daí a importância da industrialização, inclusive no caso dos bens primários (PREBISCH, 1949). Noprimeiro caso, os conhecimentos gerados são aplicados na produção, enquanto no segundo ocorre a mera assimilação dos conhecimentos existentes que leva à utilização deficiente dos fatores de produção (FURTADO, 1952).

O subdesenvolvimento é entendido não como uma etapa do desenvolvimento, mas como um processo autônomo e peculiar resultante da penetração de empresas capitalistas modernas em estruturas arcaicas (FURTADO, 1961).Assim, um moderno e restrito setor de recursos naturais tende a reforçar o caráter heterogêneo da estrutura produtiva, enquanto as oscilações no valor obtido das exportações e no valor das importações para distintos setores econômicos contribui para o desequilíbrio externo. A superação de todos esses fatores passa pela industrialização, único caminho para o desenvolvimento econômico.

Esta visão também é compartilhada por Hirschman (1961) ao destacar o papel das empresas e indústrias líderes, bem como dos efeitos de encadeamento para a frente e para trás, de modo a evitar a formação de enclaves. Kaldor(1966, 1978) também ressalta a importância da expansão e diversificação industrial para o desenvolvimento econômico, por isso países que importam bens industriais e produzem bens primários não conseguem alcançá-lo. A industrialização promove mudanças estruturais na economia no sentido do crescimento e do desenvolvimento, ou seja, mudanças de natureza quantitativa e qualitativa.

Para todos esses autores, a indústria de transformação é superior à indústria extrativa, não apenas em razão das possibilidades de aprendizagem tecnológica e geração de inovações, mas também da capacidade de absorção do excesso de mão de obra e dos efeitos de encadeamento que dela podem resultar. Portanto, para os teóricos do desenvolvimento, a abundância e a especialização em recursos naturais constituem barreiras à superação do subdesenvolvimento e do atraso econômico.

Esta visão negativa avançou com a ideia da doença holandesa apresentada por Corden e Neary (1982) e Corden (1984) e debatida até hoje. A abordagem dos autores se refere aos efeitos negativos sobre a economia holandesa decorrentes da descoberta de gás natural no final dos anos 1950 que contribuem para uma apreciação real da taxa de câmbio. As décadas de 1980 e 1990 foram então marcadas pelo surgimento da literatura empírica sobre a maldição dos recursos naturais ou resource-curse literatureque buscou evidenciar a relação negativa entre a abundância desses recursos e o desempenho econômico dos países.

Tratava-se de investigar os efeitos danosos gerados e suas possíveis causas, ainda que trabalhos posteriores tenham contestado as evidências empíricas dos estudos pioneiros como 
os de Auty (1990, 1993, 1994) e de Sachs e Warner (1995, 1997, 2001), ambos com aprimoramentos subsequentes. A literatura seguiu avançando nas décadas seguintes com estudos comparativos entre países e outros abordandocom maior profundidade a realidade de países como o Brasil, onde se verifica a expansão da produção acadêmica sobre o tema.

As contribuições de Brunnschweiler e Bulte (2008) e de Ploeg (2011) constituem referências ao mostrarem o papel determinante das instituições nos resultados alcançados. As revisões da literatura oferecidas por Frankel (2010, 2012) e Di John (2011) também merecem destaque, bem como as contribuições de Pérez (2010), Andersen e Johnson (2011) e Pérez, Marín e Navas-Alemán(2013) ao ressaltarem o papel do dinamismo tecnológico e das capacidades tecnológicas e institucionais que incluem políticas públicas direcionadoras.

Ao analisarem a evolução da literatura considerando sobretudo os estudos recentes, Maciel (2015), Pamplona e Cacciamali (2018), Ribeiro (2019) e Veríssimo (2019)destacam a ausência de consenso. A ideia inicial de uma maldição geral dos recursos naturais vem sendo substituída pela busca de entender a razão pela qual alguns países são bem-sucedidos e outros não, embora a indicação geral seja de que aqueles ricos em petróleo e gás natural são mais propensos a sofrer a maldição de acordo com a qualidade das suas instituições.

O arcabouço institucional e os arranjos institucionais são decisivos para o bom funcionamento dos mercados. O Estado deve ser ativo e indutor do desenvolvimento econômico por meio da articulação de políticas de comércio exterior, industriais e de inovação, como preconizam os autores que exploram a vertente da mudança tecnológica. A abundância de recursos naturais não se configura como bênção ou maldição, mas como oportunidade condicionada ao estabelecimento de uma estratégia de desenvolvimento de longo prazo e de políticas públicas a ela associadas.

Embora com tradição de exportação de bens primários, o Brasil emerge no centro desse debate especialmente a partir do século XXI, acompanhando o boomdas commodities decorrente da forte expansão da economia chinesa. Isso estimulou uma das vertentes do debate sobre o desenvolvimento econômico do país a partir da indústria petrolífera (BIELSCHOWSKY, 2012; CEDRO, 2014; FRISCHTAK; BELLUZZO, 2014). Contudo, ele deve ser orientado para a obtenção de vantagens competitivas sistêmicas e sustentáveis (LUMBRERAS; PIQUET, 2020)

Este boom também beneficiou a economia fluminense ao reforçar o protagonismo desta indústria alcançado com a exploração offshore pela Petróleo Brasileiro SA (Petrobras SA) na Bacia de Campos nos anos 1970 e 1980. A descoberta de grandes reservas nesta bacia sedimentar atraiu grandes investimentos para a mesorregião norte, desafiando a capacidade 
de absorção deste fluxo no âmbito do território e de análise dos seus desdobramentos sobre a região como um todo (RIBEIRO; HASENCLEVER, 2019; SANTOS, 2020).

Segundo Ribeiro (2019) e Veríssimo (2019), a indústria petrolífera pode representar uma oportunidade de desenvolvimento para o país. Em relação à economia fluminense, Marcellino et al. (2020) consideram que a especialização produtiva na indústria petrolífera tem grande potencial de promover o desenvolvimento regional, sendo para isso necessário que o governo estadual seja capaz de promover e articular políticas públicas de longo alcance.

Mas conforme assinalado por Sobral (2013), Marcellino (2016) e Mendes, Ferreira, Cavalieri (2017), os desafios dessa especialização produtiva precisam ser considerados. De acordo com Cruz e Terra (2015) e Cavalieri e Hasenclever (2019), o padrão de desenvolvimento fluminense centrado na indústria do petróleo se configura como um enclave, apresentando poucos encadeamentos produtivos e transbordamentos para a economia regional, o que encerra desafios significativos, como se pretende mostrar aqui.

\section{METODOLOGIA}

Este artigo é o resultado de uma pesquisa de natureza aplicada com finalidade descritiva voltando-se, menos para o desenvolvimento de teorias e mais para a utilização prática de conhecimentos, aplicando-os a realidades circunstanciais (GIL, 2021). Como afirma o autor, a pesquisa descritiva tem por objetivo relatar ascaracterísticas de determinada população, grupo ou fenômeno, o estabelecimento de relações entre variáveis ou mesmo a determinação da natureza destas relações.

Segundo Marconi e Lakatos (2012), as técnicas de pesquisa abrangem, tanto o conjunto de preceitos ou processos científicos, como a habilidade para usá-los, o que caracteriza a parte prática da coleta de dados. Assim, o presente artigo baseou-se no levantamento de dados e informações de fontes secundárias e primárias, de modo a permitir a descoberta de novos dados, informações, fatos, relações ou leis por meio de técnicas de documentação indireta como a pesquisa bibliográfica e documental

Em relação à pesquisa bibliográfica, foi feito um levantamento da produção acadêmicano campo da Ciência Econômica quetrata da relação entre a abundância de recursos naturais e o desenvolvimento econômico dos países com ênfase em petróleo e gás natural. O papel proeminente dessas indústrias extrativas para a economia fluminense também foi enfatizado, de modo a conectar essa literatura ao debate mais específico sobre o 
desenvolvimento regional. No que diz respeito à pesquisa documental, foram consultados dados, informações e documentos públicos de fontes oficiais nacionais e regionais.

Em âmbito nacional, foram utilizados dados disponibilizados pelo Instituto Brasileiro de Geografia e Estatística (IBGE), particularmente o Valor da Transformação Industrial (VTI) da indústria em geral e da indústria extrativa em particular que abrange petróleo e gás natural. Foi também consultada na Secretaria do Trabalhovinculada à plataforma do Ministério da Economia a Relação Anual de Informações Sociais (RAIS). Nela foram obtidos e sistematizados dados sobre empregos formais e salários médios dessa indústria, de modo a avaliar sua importância em termos de massa salarial. Foram também utilizadas informações da Agência Nacional do Petróleo, Gás Natural e Biocombustíveis (ANP) e da Câmara dos Deputados, em especial as Leis Orçamentárias Anuais (LOA).

Em âmbito regional, foram utilizados documentos publicados pela Assembleia Legislativa do Rio de Janeiro (Alerj) e pela Secretaria de Estado de Fazenda do Rio de Janeiro (Sefaz). Vale destacar que a Nota Técnica da Assessoria Fiscal da Alerj elaborada por Marcellino et al. (2020) contribuiu para a avaliação dos encadeamentos da indústria de petróleo e gás no ERJ. Os dados sobre subsídios fiscais, por sua vez, foram obtidos a partir da consulta e sistematização de estimativas divulgadas nas LOA relativas ao ERJ e no relatório intitulado "Jogando Luz na Escuridão" produzido em 2016 pelo Observatório dos Benefícios Fiscais formado por auditores fiscais da Receita do ERJ integrantes da Sefaz.

Vale destacar ainda que as informações disponibilizadas pela Sefaz, especialmente aqueles atinentes às LOA, vêm sofrendo alterações ao longo dos anos, o que impossibilitou a padronização das tabelas apresentadas na seção cinco deste artigo. Em alguns casos as informações são dispostas por setores econômicos, em outros são baseadas em leis e no caso dos subsídios fiscais, os valores correspondentes a 2010 e 2011 não foram encontrados. Por essa razão, as tabelas foram aqui sistematizadas com diferentes recortes temporais. Cabe acrescentar que os valores dos subsídios fiscais foram deflacionados considerando o Índice Nacional de Preços ao Consumidor Amplo (IPCA) divulgado pelo IBGE, de modo a permitir a comparação de valores reais e não nominais.

\section{AINDÚSTRIA PETROLÍFERA E AS POLÍTICAS NO ESTADO DO RIO DE JANEIRO}

A dimensão geopolítica é característica daindústria petrolífera que é formada por empresas internacionais privadas e nacionais de grande porte como aPetrobras SA. Ferreira 
(2015), Maciel (2015) eOliveira (2019) mostram que elas dominam segmentos da indústria, atuando de maneira diversificada e internacionalizada, integrando verticalmente as atividades de exploração, desenvolvimento e produção dos campos (upstream) àquelas que envolvem o transporte e refino do combustível, bem como sua comercialização e distribuição aos consumidores finais (downstream).

Os autores mostram também que, além de originarem a cadeia produtiva e centralizarem as possibilidades de obtenção de lucros, as atividades que compõem o segmento upstream absorvem a maior parte dos riscos, são intensivas em capital e exigem o domínio de disciplinas e tecnologias variadas, realçando a dimensão tecnológica dessa indústria que é fortemente baseada em práticas cooperativas para a geração deinovaçõessobretudo em processos. Elas são essenciais ao avanço em águas profundas e ultraprofundas, sendo também importantes as inovações em produtos.

As atividades petrolíferas são marcadas por complexidade efortes requisitos tecnológicos ede capital, governança e regulamentação estatal, dado seu caráter estratégico para países e regiões. A literatura econômica recente mostra que as altas rendas geradas em ambientes institucionais e estatais frágeis tendem a alterar as decisões de atores públicos e privados. A opção por encadeamentos fiscais em detrimento dos produtivos pode prevalecer, do mesmo modo que os retornos financeiros de curto prazodo ponto de vista das empresas, sem benefícios de longo prazo para a economia nacional ou regional.

Gobetti et al. (2020) destacam a importância econômica crescente da indústria de petróleo e gás natural no país a partir do século XXI. As receitas da produção petrolífera para o Estado brasileiro têmevoluído em geral de maneira positiva, com as participações governamentais passando de $\mathrm{R}$ \$21,6 bilhões em 2010 para $\mathrm{R} \$ 56$ bilhões em 2019. Do ponto de vista regional, o ERJtem sido o maior beneficiário, ampliando sua receita com participações governamentais de R \$ 6,4 bilhões em 2010 para R \$ 13,5 bilhões em 2019 (ANP, 2020).

A produção de petróleo e gás natural no país se dá majoritariamente no ERJ, o que favorece economicamente os municípios do estado confrontantes com as áreas produtoras (Zona de Produção Principal), apesar da expansão em direção a São Paulo (Bacia de Santos) e Espírito Santo (Bacia de Campos), dado o interesse no pré-sal devido à alta qualidade do óleo e da produtividade na exploração e produção (ARAÚJO; NAZARETH; OLIVEIRA, 2018). De fato, $85 \%$ das reservas marítimas provadas em 2019 estavam localizadas no ERJ (ANP, 2020). 
Mas em que pese a forte presença da indústria petrolífera fluminense no cenário nacional, o segmento upstream é predominante, enquanto o downstreamé relativamente frágil, sendo este justamente o segmento que concentra as melhores possibilidades de diversificação e encadeamento com outras indústrias. Estimular elos mais abrangentes, efetivos e profundos nas cadeias produtivas correlatas a essa indústria é uma questão imperativa no sentido de promover a modernização da estrutura produtiva e o desenvolvimento no estado (SILVA; MATOS, 2016).

Do ponto de vista nacional, Ferreira (2015) mostra que a preocupação com o desenvolvimento da indústria petrolífera levou o governo a promulgar o Decreto $\mathrm{n}^{\mathrm{o}}$ 4.925/2003 que instituiu o Programa de Mobilização da Indústria Nacional de Petróleo e Gás Natural (Prominp) buscando articular a implementação da política de conteúdo local iniciada pela Agência Nacional do Petróleo, Gás Natural e Biocombustíveis (ANP) em 1999 por meio da Cláusula de Conteúdo Localestabelecida nos contratos de concessão.

Ferreira (2015) e Lumbreras e Piquet (2020)também mostram o importante papel das políticas industriais. AsDiretrizes da Política Industrial, Tecnológica e de Comércio Exterior (PITCE) foram estabelecidas em 2003 e lançadas em 2004 e o fomento ao desenvolvimento industrial foi ampliado com a criação em 2007 do Programa de Aceleração do Crescimento (PAC). Os programas de consolidação e expansão da liderança dos complexos produtivos do bioetanol e do petróleo, gás e petroquímica foram destacadosna Política de Desenvolvimento Produtivo (PDP) lançada em 2008 e em 2011 surgiu o Plano Brasil Maiorvisando o desenvolvimento da cadeia energética.

Cabe acrescentar que o Regime Aduaneiro Especial de Exportação e Importação de Bens Destinados à Exploração e à Produção de Petróleo e Gás Natural (Repetro) - instituído pelo Decreto $n^{\circ} 3.161 / 1999$ e regulamentado pelo Decreto $n^{\circ}$ 6.759/2009 (Regulamento Aduaneiro) - permitiu às empresas a importação de máquinas e equipamentos ao invés de sua aquisição local, contrapondo-se às políticas de conteúdo local e industriais voltadas para a capacitação tecnológica nacional. A Lei no 13.586/2017 levou à publicação da Instrução Normativa RFB n $1.781 / 2017$ que trata do Repetro-Sped e do antigo Repetro o que, segundo Lumbreras e Piquet (2020), representa o abandono da agenda anterior de desenvolvimento econômico.

Do ponto de vista regional, ou seja, considerando leis, decretos, políticas, programas, instrumentos e mecanismosvoltados para o ERJ em abordagem retrospectiva,vale citar nos anos 1970 a criação do Banco de Desenvolvimento do Estado do Rio de Janeiro (BD-Rio) para apoiar pequenas e médias empresassubstituído nos anos 1980 pela Agência de 
Desenvolvimento do Estado do Rio de Janeiro (AD-Rio)visando a intermediação entre investidores e a implementação dos negócios. O Fundo de Desenvolvimento Econômico e Social (Fundes) surgiu na mesma época visando estimular investimentos em infraestrutura e projetos de desenvolvimento para o estado, embora tenha gerado pouco efeito sobre os investimentos (VIEIRA, 2012).

Durante os anos 1990 esse arcabouço institucional foi reformulado, tendo sido criadas agências e programas especiais de desenvolvimentosob a justificativa do acirramento da guerra fiscal e do esvaziamento da economia fluminense. Assim, a Lei Estadual $\mathrm{n}^{\circ}$ 2.273/1994 estabeleceu condições de financiamento indireto para atração de empresas agroindustriais e industriais. Em seguida, os benefícios passaram a incluir a dotação de infraestrutura e benefício fiscal de diferimento do Imposto sobre Circulação de Mercadorias e Serviços (ICMS) sem juros e com redução de correção monetária.

O Decreto Estadual n 23.012/1997, por sua vez, instituiu o Programa de Atração de Investimentos Estruturantes (Rioinvest)tendo em vista o apoio a projetos de investimento prioritários e tecnicamente viáveis. Vale destacar que ao aumentar as fontes de financiamento do Fundes por meio da Lei Estadual no 2.823/1997, a política de atração de empresas passou a ser mais discricionária, elegendo indústrias com relativa importância para a estrutura produtiva estadual, indústrias estruturantes capazes de adensar as cadeias produtivas e iniciativas de desenvolvimento das regiões menos dinâmicas do estado.

Outras regulamentações reduziram o risco de inadimplência do ERJ em relação às obrigações assumidas nas operações de subsidiamento dos projetos enquadrados pelo Rioinvest. Essa transferência de fundos públicos abrangeu ainda a dotação do território de infraestrutura de circulação nas imediações dos projetos apoiados, a exemplo do Programa de Fomento à Realização de Obras de Infraestrutura (Rioinfra) criado por intermédio da Lei Estadual n 4.186/2003. Como assinala Lencioni (2017), os fundos públicos visamà redução de incertezas e o aumento da rentabilidade dos capitais e suas frações, além de oferecer condições gerais de produção que permitam acelerar a circulação e rotação dos capitais.

Nos primeiros anos doséculo XXI, sob os auspícios da atração de empresas e da geração de empregos no ERJ, mais de quinze leis e decretos foram estabelecidos tendo em vista o suporte a indústrias relevantes levando em conta a estrutura produtiva estadual como as indústrias petrolífera, naval e náutica. Vale citar as indústrias têxtil, de eletrônicos e cosméticos, as indústrias de fármacos e atacadista, bem como as indústrias de material de construção civil e química. Vale citar também as indústrias de bens de capital e de consumo duráveis, além das indústrias de informática, calçados, joias e bebidas. 
Diferentemente das medidas e ações estabelecidas em anos anteriores relacionadas ao crédito subvencionado via Fundes, as políticas industriais estaduais recentes foram baseadas nos benefícios tributários vinculados ao ICMS. A essas medidas com viés setorial se somaram outras considerando as dimensões territorial e regional envolvendo a criação de distritos industriais, a instalação de termelétricas e estabelecimentos industriais ligados às atividades do Porto de Sepetiba, além daquelas voltadas para a institucionalização dos fundos de recuperação regional.

Destaca-se no âmbito setorial que constitui o objeto deste artigo o surgimento da primeira iniciativa deapoio ao desenvolvimento da indústria petrolífera fluminense. $\mathrm{O}$ Decreto Estadual $\mathrm{n}^{\mathrm{o}}$ 24.270/1998instituiu o Programa Setorial de Desenvolvimento da Indústria do Petróleo no Estado do Rio de Janeiro (Riopetróleo). Houve decretos subsequentes alterando incisos, tendo ocorrido a revogação do Programa Riopetróleo por intermédio do Decreto Estadual $n^{\circ} 40.879 / 2007$. Vale dizer que os projetos nele enquadrados foram contemplados com recursos do Fundes.

A Lei Estadual no 3.851/2002, de caráter extraorçamentário, reduziu a incidência do ICMS sobre a importação de bens e serviços iniciados no exterior e que fossem aplicados às atividades de produção petrolífera no litoral do estado. O Decreto Estadual no 41.442/2008, por sua vez, considerando o Repetroconsagrado via Convênio ICMS n $130 / 2007$, permitiu a importação de equipamentos sem o recolhimento do ICMS.

Por fim, o Decreto Estadual n 46.233/2018 estabeleceu a isenção e redução da base de cálculo do ICMS incidente em operações relativas a bens ou mercadorias aplicados às atividades de exploração e produção de petróleo e gás natural. Ele foi revogado pela Lei Estadual $n^{\circ} 8.890 / 2020$ que, nos termos do Convênio ICMS nº 03/2018 e do Convênio ICMS n 220/2019, estabeleceu a redução da base de cálculo do ICMS limitada a 3\% nas operações de importação e aquisições internas de bens e mercadorias no âmbito do Repetro-SPED e do Repetro-Industrialização, bem como o diferimento do imposto sobre operações internas e externas.

As leis e decretos estaduais citados anteriormente envolvendo desde o uso do Fundes até os recursos extraorçamentáriosrelativos ao ICMS como diferimento e redução do imposto visavam, tanto o desenvolvimento da indústria de petróleo e gás fluminense, como a atração de investimentos externos, a geração de empregos, o encadeamento intersetorial e a modernização e ampliação das empresas existentes. As especificidades dessa indústria e as implicações desse arcabouço político-regulatório são apresentadas a seguir. 


\section{A DINÂMICA DA INDÚSTRIA PETROLÍFERA NO ESTADO DO RIO DE JANEIRO}

Os sucessivos subsídios fiscais dirigidos aos setores industriais e as medidas voltadas ao desenvolvimento territorial e regional implementados no ERJ considerando as estimativas das LOA apresentaram valores reais superiores a $\mathrm{R} \$ 70$ bilhões nos anos 2010. O maior incremento das renúncias ocorreu entre 2012 e 2015 seguido de estabilização, acompanhando a crise econômica e política e sendo formado principalmente pela modalidade creditícia (ICMS). Do ponto de vista setorial, a indústria de petróleo e combustível foi a principal beneficiada acompanhada pelas indústrias química e petroquímica, como mostra a Tabela 1.

Essa concentração de subsídios fiscais reflete o conjunto de políticas industriais implementadas desde o final do século XX como Riopetróleo eRepetro-Industrialização destinadas a apoiar o desenvolvimento da indústria de petróleo e gás no ERJ, especialmente por meio da atração de novos investimentos, do adensamento das cadeias produtivas e da geração de empregos.

Tabela 1 -SubsídiosFiscaispor Setor Econômico no Período2012-2016(\%)

\begin{tabular}{lccccc}
\hline Setores & $\mathbf{2 0 1 2}$ & $\mathbf{2 0 1 3}$ & $\mathbf{2 0 1 4}$ & $\mathbf{2 0 1 5}$ & $\mathbf{2 0 1 6}$ \\
\hline Bebidas & 1,0 & 0,7 & 1,3 & 1,5 & 1,8 \\
Editorial e Gráfica & 0,6 & 0,6 & 0,6 & 0,3 & 0,3 \\
Energia Elétrica & 1,1 & 3,5 & 1,4 & 2,8 & 2,3 \\
Outros & 8,8 & 10,1 & 9,3 & 8,6 & 7,4 \\
Petróleo e Combustível & 25,8 & 31,1 & 1,9 & 20,9 & 18,3 \\
Produtos Alimentícios & 2,3 & 1,8 & 23,8 & 7,7 & 10,9 \\
Produtos Farmacêuticos, Perfumaria, Cosméticos e Materiais Médicoscos & 11,8 & 11,8 & 5,9 & 12,6 & 14,4 \\
Química e Petroquímica & 7,5 & 6,4 & 4,1 & 6,6 & 6,8 \\
Serviço de Comunicação & 2,6 & 0,7 & 0,5 & 1,6 & 1,0 \\
Serviço de Transporte & 1,9 & 4,8 & 1,6 & 1,2 & 1,1 \\
Setor Viário & 1,0 & 1,2 & 2,4 & 0,9 & 1,1 \\
Siderurgia e Metalurgia e Material de Construção & 8,9 & 6,6 & 28,6 & 11,2 & 13,4 \\
Supermercado, Eletroeletrônico e Lojas de Departamento & 11,1 & 5,3 & 2,5 & 10,2 & 7,7 \\
Têxtil e Vestuário & 15,5 & 15,5 & 16,2 & 14,0 & 13,0 \\
Energia Elétrica Convênio & 0,0 & 0,0 & 0,0 & 0,0 & 0,3 \\
\hline Total & $\mathbf{1 0 0}$ & $\mathbf{1 0 0}$ & $\mathbf{1 0 0}$ & $\mathbf{1 0 0}$ & $\mathbf{1 0 0}$ \\
\hline Fonte: Elaboração dos autores a partir da SEFAZ (2020). & & & & &
\end{tabular}

Fonte: Elaboração dos autores a partir da SEFAZ (2020).

Contudo, parcela expressiva dos subsídios se mantém concentrada em poucas empresas, com destaque para aquelas com atuação na indústria de petróleo e gás. Desconsiderando o varejo eos serviços de utilidade pública como a distribuição de água e 
energia, as principais empresas beneficiárias dos subsídios foram Petrobras, Petrobras Distribuidora, Baker Hughes e Brasfels, como mostra a Tabela 2.

Tabela 2 -Principais Empresas do ERJ Beneficiadas com Subsídios Fiscais

\begin{tabular}{llcc}
\hline & Empresas & $\mathbf{R}$ & $\mathbf{\%}$ \\
\hline 01 & GE Celma Ltda & 5.826 .918 .725 & $19,8 \%$ \\
02 & Ampla Energia e Serviços SA & 2.246 .824 .024 & $7,6 \%$ \\
03 & Petróleo Brasileiro SA & 2.186 .618 .832 & $7,4 \%$ \\
04 & Companhia Estadual de Águas e Esgotos (Cedae) & 1.471 .724 .520 & $5,0 \%$ \\
05 & Casas Guanabara Comestíveis Ltda & 917.898 .445 & $3,1 \%$ \\
06 & Petrobras Distribuidora SA & 789.189 .901 & $2,7 \%$ \\
07 & Prezunic Comercial Ltda & 768.575 .698 & $2,6 \%$ \\
08 & Baker Hughes do Brasil Ltda & 590.820 .888 & $2,0 \%$ \\
09 & Light Serviços de Eletricidade SA & 521.522 .287 & $1,8 \%$ \\
10 & Brasfels SA & 513.886 .275 & $1,7 \%$ \\
\hline
\end{tabular}

Fonte: Elaboração dos autores a partir do Observatório dos Benefícios (2016).

A renúncia fiscal abrangeu a exploração e produção de petróleo e gás (Petrobras), a distribuição de derivados de petróleo (Petrobras Distribuidora), os produtos e serviços para exploração e produção de petróleo (BakerHughes) e os serviços de construção, conversão, atualização e reparo (Brasfels). Somente a exploração, produção e distribuição, todas sob o comando da Petrobras, responderam por mais de $10 \%$ de todos os subsídios fiscais vinculados às leis e decretos de apoio à indústria petrolífera fluminense.

Considerando o Valor da Transformação Industrial (VTI), a indústria fluminenseé caracterizada pela prevalência das atividades de extração de petróleo e gás natural, fabricação de coque, de produtos derivados do petróleo e de biocombustíveis. O conjunto de benefícios fiscais tem se voltado no sentido de favorecer e reforçar as atividades já existentes e consolidadas na estrutura produtiva estadual, como pode ser observado na Tabela 3.

Tabela 3 -VTI da Indústria de P\&Gno ERJ (2010-2018) (\%)

\begin{tabular}{|c|c|c|c|c|c|c|c|c|c|}
\hline Atividades Econômicas & 2010 & 2011 & 2012 & 2013 & 2014 & 2015 & 2016 & 2017 & 2018 \\
\hline Indústrias Extrativas & 32,5 & 34,9 & 38,2 & 38,7 & 43,4 & 40,1 & 39,6 & 40,5 & 39,6 \\
\hline Extração de Petróleo e Gás Natural & 27,0 & 28,6 & 31,5 & 31,6 & 35,8 & 31,3 & 33,5 & 35,2 & 35,1 \\
\hline $\begin{array}{l}\text { Atividades de Apoio à Extração de } \\
\text { Minerais }\end{array}$ & 5,2 & $X$ & $X$ & 6,5 & 7,1 & 8,2 & 5,6 & 5,1 & $X$ \\
\hline Indústrias de Transformação & 67,5 & 65,1 & 61,8 & 61,3 & 56,6 & 59,9 & 60,4 & 59,5 & 60,4 \\
\hline $\begin{array}{l}\text { Fabricação de Coque, de Produtos } \\
\text { Derivados do Petróleo e de } \\
\text { Biocombustíveis }\end{array}$ & 22,4 & 22,5 & 20,0 & 17,1 & 14,2 & 16,4 & 16,8 & 22,5 & 25,3 \\
\hline $\begin{array}{l}\text { Sistema Produtivo de P\&G } \\
\text { (Upstream e Downstream) }\end{array}$ & 54,6 & 51,1 & 51,5 & 55,2 & 57,0 & 55,8 & 55,9 & 62,8 & 60,3 \\
\hline
\end{tabular}

Fonte: Elaboração dos autores a partir do IBGE (2020). 
Os dados indicam certo padrão de especialização devido ao peso crescente das indústrias extrativas impulsionadas pela extração e produção de petróleo e gás no VTI da indústria fluminense, passando de 32,5\% em 2010 para 39,6\% em 2018. No segment upstream, a participação do ERJ corresponde a mais da metade do VTI deste segmento em âmbito nacional. As atividades de apoio à extração de minerais amplamente impulsionada pela exploração e produção, apesar de responderem por apenas 5\% do VTI do ERJ perfazem, em âmbito nacional, mais de $80 \%$ do VTI deste segmento, o que indicaa prevalência do ERJ (MARCELLINO et al., 2020).

O segmento downstream destacou-se no conjunto da indústria de transformação estadual, correspondendo a mais de $25 \%$ do VTI das atividades industriais. Diferentemente da extração e produção, bem como dos serviços vinculados, o segmento downstream não se concentra no território fluminense, conforme assinalado por Silva e Matos (2016). Isso indica uma "capacidade relativamente menor de gerar encadeamentos produtivos para a frente, isto é, nas atividades que utilizam os derivados gerados pelo refino, principalmente em outros segmentos industriais" (MARCELLINO et al., 2020, p. 6).

Neste segmento, a capacidade de refino no ERJ não se alterou em uma década, passando de 256 mil barris/dia em 2010 para 261 mil barris/dia em 2019 (ANP, 2020). Isso retrataa baixa capacidade de geração de novas ocupações e de renda, apesar das expectativas elevadas com a construção - interrompida e em parte retomada - do Complexo Petroquímico do Rio de Janeiro (Comperj) em Itaboraí - que incluía uma refinaria da Petrobras com previsão de entrada em operação em 2013 (BARRIGA, 2020).

Estes resultados também são congruentes com o estudo de Silva (2007) que identificou no downstream a importância relativa do refino de petróleo na multiplicação da renda e do emprego nacional. A autora identificou a falta de maior encadeamento das atividades intrarregionais no ERJ, além da fragilidade na estrutura produtiva estadual decorrente da baixa integração setorial e interregional. Em consequência, é relativamente alta a dependência das relações comerciais intrarregionais e das relações com o estado de São Paulo.

Apesar da ênfase no encadeamento setorial e na integração vertical das atividades no território fluminense a partir de um intrincado sistema de benefícios dirigido à indústria petrolífera, a internalização parece estar aquém das renúncias fiscais. Segundo Marcellino et al. (2020), apenas $17 \%$ dos gastos da Petrobras são feitos com fornecedores do ERJ, enquanto $70 \%$ são efetivados com empresas situadas no exterior, especialmente ligadas à construção naval e offshore. Considerando que o maior volume do petróleo nacional é 
proveniente do ERJ, parcela considerável da riqueza relacionada à exploração, produção e refino de petróleo e gás realizada pela Petrobrás "vaza" para fora do estado.

Além disso, o Repetro parece ter funcionado no sentido contrário ao que foi estabelecido pela política industrial estadual, pois estimula as importações em detrimento das compras de fornecedores locais. Os benefícios da adesão do ERJ a esse marco regulatórionão têm sido verificáveis. Oliveira (2021) defende a remoção dos incentivos tributários vinculados ao Repetro cujos estímulos às compras externas de bens e serviços penaliza os fornecedores fluminenses. Enquanto não ocorrer essa alteração, ele propõe a cobrança adicional do ICMS das operadoras que não cumprirem o conteúdo local assumido nos contratos de seus projetos aprovados.

As atividades envolvendo a indústria de petróleo e gás no ERJ aumentaram sua participação na geração de empregos formais em relação à indústria de transformação, passando de 35,6\% em 2010 para 42,7\% em 2019. Embora este aumento envolva mais um componente relativo do que absoluto, posto que ocorre por conta de uma queda menor dessas atividades vis-à-vis a indústria de transformação no período, os dados indicam a importância dos segmentos da indústria petrolífera no conjunto da indústria de transformação do ERJ no que se refere aos empregos diretos, como pode ser visualizado na Tabela 4.

Tabela 4 -Empregos Formais na Indústria de P\&G no ERJ (2010-2019)

\begin{tabular}{|c|c|c|c|c|c|c|c|c|c|c|c|}
\hline Setores & 2010 & 2011 & 2012 & 2013 & 2014 & 2015 & 2016 & 2017 & 2018 & 2019 & $\begin{array}{c}\text { Var } \\
\%\end{array}$ \\
\hline $\begin{array}{l}\text { Fornecedores e } \\
\text { Prestadores de } \\
\text { Serviços }\end{array}$ & 34870 & 37062 & 45410 & 50709 & 55950 & 41103 & 30340 & 29210 & 26559 & 34960 & 0,3 \\
\hline $\begin{array}{l}\text { Exploração e } \\
\text { Produção }\end{array}$ & 32909 & 35549 & 39895 & 41274 & 41044 & 37053 & 30651 & 28333 & 27769 & 31635 & $-3,9$ \\
\hline $\begin{array}{l}\text { Refino e Produção } \\
\text { de Derivados }\end{array}$ & 15244 & 17255 & 17885 & 18262 & 17968 & 17528 & 16962 & 14431 & 15396 & 16780 & 10,1 \\
\hline $\begin{array}{l}\text { Petroquímica e } \\
\text { Indústria de } \\
\text { Plásticos }\end{array}$ & 19634 & 20784 & 20817 & 21875 & 22036 & 19960 & 17178 & 16928 & 16055 & 13029 & $-33,6$ \\
\hline $\begin{array}{l}\text { Distribuição e } \\
\text { Comercialização }\end{array}$ & 36309 & 36687 & 37160 & 36705 & 38067 & 39302 & 39148 & 38706 & 36675 & 37860 & 4,3 \\
\hline $\begin{array}{l}\text { Indústria de } \\
\text { P\&G }\end{array}$ & $\begin{array}{c}13896 \\
6 \\
\end{array}$ & $\begin{array}{c}14733 \\
7 \\
\end{array}$ & $\begin{array}{c}16116 \\
7 \\
\end{array}$ & $\begin{array}{c}16882 \\
5\end{array}$ & $\begin{array}{c}17506 \\
5\end{array}$ & $\begin{array}{c}15494 \\
6 \\
\end{array}$ & $\begin{array}{c}13427 \\
9\end{array}$ & $\begin{array}{c}12760 \\
8 \\
\end{array}$ & $\begin{array}{c}12245 \\
4 \\
\end{array}$ & $\begin{array}{c}13426 \\
4 \\
\end{array}$ & $-3,4$ \\
\hline $\begin{array}{l}\text { Indústria de } \\
\text { Transformação }\end{array}$ & $\begin{array}{c}39062 \\
9 \\
\end{array}$ & $\begin{array}{c}40438 \\
1 \\
\end{array}$ & $\begin{array}{c}41398 \\
5 \\
\end{array}$ & $\begin{array}{c}41400 \\
1 \\
\end{array}$ & $\begin{array}{c}41312 \\
8 \\
\end{array}$ & $\begin{array}{c}36984 \\
6 \\
\end{array}$ & $\begin{array}{c}33035 \\
2 \\
\end{array}$ & $\begin{array}{c}31992 \\
4 \\
\end{array}$ & $\begin{array}{c}30887 \\
7 \\
\end{array}$ & $\begin{array}{c}31431 \\
4 \\
\end{array}$ & $-19,5$ \\
\hline Total ERJ & $\begin{array}{c}40800 \\
82 \\
\end{array}$ & $\begin{array}{c}43490 \\
52\end{array}$ & $\begin{array}{c}44617 \\
06\end{array}$ & $\begin{array}{c}45867 \\
90\end{array}$ & $\begin{array}{c}46413 \\
80\end{array}$ & $\begin{array}{c}44488 \\
59\end{array}$ & $\begin{array}{c}41594 \\
81\end{array}$ & $\begin{array}{c}40447 \\
36 \\
\end{array}$ & $\begin{array}{c}40174 \\
81\end{array}$ & $\begin{array}{c}40384 \\
49\end{array}$ & $-1,0$ \\
\hline
\end{tabular}

Fonte: Elaboração dos autores a partir da RAIS (2021).

O crescimento do número de empregos na indústria de transformação foi interrompido em 2013, enquanto nas atividades vinculadas à indústria petrolífera isso ocorreu 
a partir de 2015. Ao final da série, a queda da indústria de transformação foi de $19,5 \%$, enquanto a queda das atividades da indústria de petróleo e gás natural foi bem menor, ou seja, de apenas $3,4 \%$.

Alguns segmentos da indústria petrolífera - como refino e produção de derivados, distribuição e comercialização e fornecedores e prestadores de serviços - recuperaram os níveis de emprego em relação ao ano inicial, contribuindo para o incremento do percentual dessa indústria no conjunto dos empregos da indústria de transformação. Já as indústrias que se situam à jusante - como petroquímica e plásticos - foram marcadas por elevada retração nos empregos $(-33,6 \%)$, o que mostra o baixo grau de encadeamento existente na estrutura produtiva regional.

O segmento de exploração e produção de petróleo e gás natural exerce forte efeito nas atividades relacionadas aos fornecedores e prestadores de serviços cuja importância, em termos de emprego, é maior do que a própria exploração e produção no ERJ. Até 2014, esses dois segmentos foram beneficiados pelos aumentos dos investimentos e de empregos, na medida em que a expansão da exploração e produção levou ao incremento das atividades de fornecedores e prestadores de serviços.

A partir de 2014, no entanto, alguns fatores modificaram a conjuntura: 1) redução dos preços do petróleo no mercado internacional; 2) impactos da crise político-institucional; 3) flexibilização da política de conteúdo local; 4) reorientação estratégica da Petrobras e implicações nos empregos de exploração e produção, bem como nos fornecedores e prestadores de serviços (MARCELLINO et al., 2020, p. 7). Com isso, o segmento de fornecimento e prestação de serviços sofreu com a perda de postos de trabalho.

Além dos postos de trabalho formais, as atividades vinculadas à indústria petrolífera exercem forte influência na composição da renda na economia fluminense. Conforme salientado por Marcellino et al., (2020), enquanto o salário médio dos trabalhadores formais no ERJ gira em torno de R \$3.282,71 e na indústria de transformação o salário médio é de R\$ 4.606,26, nas atividades relacionadas à indústria de petróleo e gás, o salário médio é de R \$ 9.280,31. Essa particularidade tem reflexo na massa salarial, como mostra a Tabela 5.

Tabela 5 - Massa Salarial Percentual da Indústria de P\&G no ERJ (2010-2019) 


\begin{tabular}{lcccccccccc}
\hline \multirow{2}{*}{ Segmentos de P\&G } & $\mathbf{2 0 1 0}$ & $\mathbf{2 0 1 1}$ & $\mathbf{2 0 1 2}$ & $\mathbf{2 0 1 3}$ & $\mathbf{2 0 1 4}$ & $\mathbf{2 0 1 5}$ & $\mathbf{2 0 1 6}$ & $\mathbf{2 0 1 7}$ & $\mathbf{2 0 1 8}$ & $\mathbf{2 0 1 9}$ \\
\cline { 2 - 9 } & $\mathbf{1 0 0}$ & $\mathbf{1 0 0}$ & $\mathbf{1 0 0}$ & $\mathbf{1 0 0}$ & $\mathbf{1 0 0}$ & $\mathbf{1 0 0}$ & $\mathbf{1 0 0}$ & $\mathbf{1 0 0}$ & $\mathbf{1 0 0}$ & $\mathbf{1 0 0}$ \\
\hline Fornecedores/Prestadores de & 16,6 & 16,6 & 18,5 & 20, & 22,0 & 18,5 & 18,8 & 18,7 & 17,6 & 22,4 \\
Serviços & & & & & & & & & & \\
Exploração e Produção & 42,1 & 41,9 & 43,1 & 43,0 & 42,1 & 41,4 & 38,5 & 37,9 & 39,6 & 43,8 \\
Refino e Produção de Derivados & 26,5 & 27,5 & 25,7 & 25,0 & 24,1 & 27,1 & 29,0 & 28,1 & 30,4 & 21,1 \\
Petroquímica e Indústria de & 4,5 & 4,3 & 4,5 & 4,6 & 4,5 & 4,7 & 4,6 & 5,3 & 5,0 & 3,5 \\
Plásticos & & & & & & & & & & \\
Distribuição e Comercialização & 10,3 & 9,7 & 8,1 & 7,2 & 7,2 & 8,3 & 9,2 & 10,0 & 7,3 & 9,3 \\
\hline Indústria de P\&G/Total ERJ & $\mathbf{9 , 2 \%}$ & $\mathbf{9 , 8 \%}$ & $\mathbf{1 0 , 3}$ & $\mathbf{1 0 , 5}$ & $\mathbf{1 0 , 6}$ & $\mathbf{1 0 , 1}$ & $\mathbf{9 , 4}$ & $\mathbf{8 , 7}$ & $\mathbf{8 , 6}$ & $\mathbf{8 , 0}$ \\
\hline
\end{tabular}

Fonte: Elaboração dos autores a partir da RAIS (2021).** Participação relativa do setor de P\&G na massa salarial do ERJ.

Marcellino et al. (2020, p. 7) destacam ainda que as "atividades com maiores salários nesse sistema produtivo eram aquelas ligadas à cadeia de fornecedores e prestadores de serviço, à extração de fato (exploração e produção) e às atividades de refino e produção de derivados". As atividadesenvolvendo fornecimento e prestação de serviços foram as que mais ampliaram sua importância na composição da massa salarial dentro da indústria de $\mathrm{P} \& \mathrm{G}$, aumentando de $16,6 \%$ para $22,4 \%$. Contudo, são as atividades de exploração e produçãoaquelas que melhor explicam a massa salarial no interior da indústria de petróleo e gás por representarem mais de $40 \%$.

No conjunto da economia estadual, houve pequena queda na indústria de petróleo e gás de $9,2 \%$ para $8 \%$ da massa salarial na série analisada, muito por conta da queda de participação percentual dos segmentos de refino e produção de derivados, bem como da petroquímica e indústria de plásticos.Estes segmentos perderam, inclusive, participação na massa salarial dentro da indústria de transformação, caindo de 25,9\% em 2010 para 23,2\% em 2019.

Como destacam Chambriard e Neves (2020), além do emprego direto e dos efeitos sobre a renda em termos nacionais,a indústria petrolífera também exerce efeitos sobre a demanda de bens e serviços na economia regional, contribuindo para geração de empregos indiretos. Contudo, segundo os autores, as características tecnológicas e de exploração podem implicar na variação dos empregos. A produção em terra (onshore) tende a ser menos intensiva em capital e a gerar mais postos de trabalho vis-à-vis a produção no mar (offshore). Neste sentido, torna-se imperiosa a elaboração e implementação de políticas públicas de geração de empregos e a reabilitação de campos terrestres e marítimos em águas rasas.

Considerando as particularidades da exploração e produção de petróleo no ERJ com a hibernação dos campos maduros em águas rasas na Bacia de Campos e a priorização dos campos de petróleo em águas ultra profundas, o cenário futuro é de redução dos empregos e 
da renda no segmento de exploração e produção. Chambriard e Neves (2020) salientam que, para expandir a geração de empregos, será preciso definir o papel da indústria brasileira no desenvolvimento do setor de petróleo, exigindo uma decisão política que internalize parte dos próximos investimentos. Trata-se de uma disputa política em torno da renda petroleira nos primeiros elos da cadeia produtiva.

Com base nos resultados aqui apresentados, apesar do peso significativo da indústria de petróleo e gás no conjunto da indústria fluminense e considerando os elevados subsídios fiscais destinados aos segmentos dessa indústria, a política de fomento estadual parece não ter logrado êxito em promover maior encadeamento e diversificação industrial. Como aponta a literatura, em especial Marcellino et al., (2020), a adesão do ERJ ao Repetroe as características da indústria petrolífera tornam indicam que parte importante dos elos da cadeia de petróleo é importada. O que se verifica é a importação de bens, equipamentos e serviços alugados ou adquiridos via regime de afretamentosem o reforço efetivo dos encadeamentos produtivos a partir das atividades de exploração e produção de petróleo e gás natural, cabendo ao ERJ atividadesde apoio à extração de petróleo e gás enavegação de apoio.

Os segmentos vinculados à indústria petrolífera são marcados pela atuação de capitais internacionais móveis com atuação multiescalar e por uma rede de fornecedores que transcende a escala nacional. As políticas regionais de fomento à indústria petrolíferase justificam se, de fato, possibilitarem o adensamento das cadeias produtivas a ela vinculadas, bem como o aproveitamento das externalidades positivas por ela geradas.

Portanto, é fundamental repensar as políticas estaduais de fomento à indústria de petróleo e gás natural, de modo a estimular elos de cadeias não internalizados no estado, apoiar a exploração em águas rasas com maior propensão a gerar empregos eestimularas atividades do segmento downstream com políticas voltadas ao fortalecimento e maior enraizamento de empresas de toda a cadeia petroquímica, da primeiraà terceira geração. É preciso considerar o dinamismodeste segmento e suas possibilidadesde gerar benefícios econômicos a outras indústrias do estado, ampliando também a geração de emprego e renda.

Dada a especialização produtiva do ERJ na indústria petrolífera, políticas de longo prazo são necessárias no sentido de integrar os agentes econômicos em projetos cooperativos de desenvolvimento, evitando práticas rentistas que fragilizam asinstituições. Trata-se debuscar o maior aproveitamento do progresso técnico nessa indústria, de modo a evitar a economia de enclave que reforçaa heterogeneidade estruturale não permite a disseminação de externalidades positivas. 
No entanto, o fortalecimento da indústria de transformação no estado a partir da cadeia produtiva do petróleo não irá ocorrer de maneira automática, dependendo do estabelecimento de uma estratégia de desenvolvimento e de ações consequentes. A oferta de bens e serviços presume um nível crescente de qualidade e produtividade capazes de reduzir a dependência do ERJ de políticas que possam ser contestadas por excessivo protecionismo em relação aos demais estados da federação.

Com relaçãoao diferimento do ICMS, convémrestringir este benefício apenas a empresas que cumpram percentuais mínimos de conteúdo local. $\mathrm{O}$ arranjo normativo atual não favorece o adensamento das cadeias produtivas, reforçando mais propriamente os interesses das empresas que atuam na indústria petrolífera, limitando-se à transferência de fundos públicos. $\mathrm{Na}$ verdade, eles acabam por reforçar a consolidação de uma estrutura produtiva especializada e com pouca propensão a dinamizar as demais atividades, além de comprometer as finanças do estado que perde receita tributária.

\section{CONSIDERAÇÕES FINAIS}

Este artigo pretendeu contribuir para o atual e oportuno debate sobre a importância de políticas públicas voltadas para o desenvolvimento econômico do estado do Rio de Janeiro tendo como prisma analítico a cadeia produtiva de petróleo e gás e as possibilidades de geração de externalidades positivas, dada a centralidade das mesmas para a temática do desenvolvimento regional.

Verificou-se que a atração de investimentos para o estado tendo em vista o aumento dos níveis de produção, emprego e renda apresentou resultados limitados. Parte expressiva dos subsídios fiscais oferecidos se concentrou em poucas empresas petrolíferas com destaque para a Petrobras, tanto no segmento de exploração e produção que é predominante no estado, como de distribuição de derivados. Vale citar a Baker Hughes que oferece produtos e serviços voltados para o primeiro segmento e o estaleiro Brasfels que presta serviços de construção, conversão, atualização e reparo.

As atividades do segmento de exploração e produção dão origem à cadeia petrolífera, absorvem a maior parte dos riscos, centralizam as possibilidades de obtenção de lucros, são intensivas em capital e exigem o domínio de múltiplas disciplinas e tecnologias, realçando a dimensão tecnológica dessa indústria. Elas exercem forte influência sobre os fornecedores favorecendo a geração de empregos, o que ocorreu sobretudo até 2014. Contudo, a Petrobras destina hoje menos de $20 \%$ dos recursos disponíveis para fornecedores localizados no ERJ, 
enquanto a maior parte se dirige a empresas sediadas no exterior, o que fragiliza o encadeamento produtivo regional.

As atividades do segmento de exploração e produção também exercem forte influência sobre a geração de renda para a economia fluminense, uma vez que representam cerca de $40 \%$ da massa salarial da indústria de petróleo e gás, percentual significativamente maior quando comparado àqueles observados nos demais segmentos dessa indústria. Tal segmento envolve atividades complexas, requerendo profissionais altamente qualificados que percebem elevados salários. Nele se combinam distintas capacitações, além de equipamentos e serviços que envolvem diferentes bases tecnológicas e graus de maturidade,

As informações obtidas ratificam o padrão de especialização da economia fluminense em bens primários apontado pelos teóricos do desenvolvimento e também por estudos anteriores que destacam o papel preponderante do segmento de exploração e produção petrolífera. Apesar dos efeitos positivos em termos de emprego e renda, essas atividades não são capazes de levar ao desenvolvimento regional por si mesmas, posto que geram poucos encadeamentos a montante por serem intensivas em capital.

A literatura econômica recente mostra que o contexto institucional é decisivo para o bom funcionamento dos mercados. A trajetória de desenvolvimento econômico passa por um Estado ativo porque capaz de articular políticas de comércio exterior, industriais e de inovação. Ela mostra ainda que a abundância de recursos naturais como petróleo e gás natural não é uma bênção ou maldição em si,podendo se tornar uma oportunidade se condicionada ao estabelecimento de uma estratégia de mudanças estruturais de longo prazo e de políticas públicas a ela vinculadas.

Assim, é fundamental a retomada de políticas nacionais para a indústria petrolífera voltadas para a melhoria das condições de infraestrutura, o fortalecimento da indústria nacional de fornecedores de bens e serviços, a formação de recursos humanos em diversos níveis e a geração e transferência de conhecimentos científico-tecnológicos de fronteira. No entanto, a articulação entre políticas nacionais e regionais é essencial, de modo a estimular o comportamento cooperativo dos agentes econômicos em uma perspectiva de longo prazo.

A importância geopolítica da indústria petrolífera e seu papel no desenvolvimento econômico nacional e regional ratificam a importância do debate sobre um projeto nacional para a economia do petróleo que oriente o planejamento e a reindustrialização no estado do Rio de Janeiro, de modo a evitar a manutenção de uma estrutura produtiva frágil por não ser capaz de gerar encadeamentos produtivos importantes e externalidades positivas. 
Espera-se que este artigo tenha cumprido o objetivo de contribuir para a reflexão e composição de uma agenda de políticas públicas para o desenvolvimento econômico do estado do Rio de Janeiro ao enfatizar a importância da criação de vantagens competitivas sistêmicas e sustentáveis. Em relação a pesquisas futuras, recomenda-se o aprofundamento da visão regional a partir de opiniões e percepções de especialistas nos temas tratados por meio da realização de entrevistas e trabalhos de campo, de modo a complementar os resultados aqui obtidos.

\section{REFERÊNCIAS}

AGÊNCIA NACIONAL DO PETRÓLEO, GÁS NATURAL E BIOCOMBUSTÍVEIS (ANP). Anuário Estatístico Brasileiro do Petróleo, Gás Natural e Biocombustíveis. [Relatório Anual]. ANP, Rio de Janeiro, RJ, Brasil, 2020.

AMARAL FILHO, J. A endogeneização no desenvolvimento econômico regional e local. Planejamento e PolíticasPúblicas, n. 23, p. 261-286, 2001.

ANDERSEN, A. D.; JOHNSON, B. Monocausalism versus systems approach to development: the possibility of natural resource-based development.Aalborg University. Aalborg: Denmark, 2011.

ARAÚJO, N. Q.; NAZARETH, P. A.; OLIVEIRA, H. D. As rendas petrolíferas dos municípios do Rio de Janeiro e de São Paulo e o pré-sal. BoletimPetróleo, Royalties e Região, Ano XVI, n. 59, p. 3-9, 2018.

AUTY, R. M. Resource-based industrialization: sowing the oil in eight developing countries. Oxford: Clarendon Press, 1990.

AUTY, R. M. Sustaining development in mineral economies: the resource curse thesis. London: Routledge, 1993.

AUTY, R. M. Industrial policy reform in six large newly industrialising countries: the resource curse thesis. World Development, v. 22: n. 1, p. 11-26, 1994.BARRIGA, A. Da aventura petroquímica do Comperj ao pé no chão da planta de lubrificantes básicos. EPBR. Matéria publicada em 2020. Disponível em: https://epbr.com.br/da-aventurapetroquimica-do-comperj-ao-pe-no-chao-da-planta-de-lubrificantes-basicos-por-albertobarriga/. Acesso em: 23 mar. 2021.

BIELSCHOWSKY, R. Estratégia de desenvolvimento e as três frentes de expansão no Brasil: um desenho conceitual. Economia e Sociedade, v. 21, número especial, p. 729-747, 2012. 
BRITTO, J.; CASSIOLATO, J. E. \& MARCELLINO, I. S. Especialização e dinamismo inovativo da indústria fluminense: desafios e potencialidades para o desenvolvimento regional. In: OSORIO, M.; MELO, L. M.; VERSIANI, M. H. \& WERNECK, M. L. (Orgs.). Uma agenda para o Rio de Janeiro: estratégicas e políticas públicas para o desenvolvimento sócio-econômico.Rio de Janeiro: FGV Editora, 2015, p. 143-195.

BRUNNSCHWEILER, C. N.; BULTE, E. H. The resource curse revisited and revised a tale of paradoxes and red herrings. Journalof Environmental Economicsand Management, v. 55, n. 3, p. 248-264, 2008.

CAVALIERI, H.; HASENCLEVER, L. Especialização produtiva: reflexos sobre o desenvolvimento do estado do Rio de Janeiro. Cadernos do Desenvolvimento Fluminense, n. 16, p. 11-25, 2019.

CEDRO, R. C. A estratégia do pré-sal como política de desenvolvimento nacional. Cadernos do Desenvolvimento, v. 9, n. 14, p. 105-117, 2014.

CHAMBRIARD, M.; NEVES, P. Petróleo, gás natural, emprego e renda: estimativas para 2030. CadernoOpinião, p. 4-15, 2020.

CORDEN, W. M. Booming sector and Dutch Disease Economics: survey and consolidation. Oxford Economics Papers, v. 36, n. 3, p. 359-380, 1984.

CORDEN, W. M.; NEARY. J. P. Booming sector and de-industrialization in a small open economy. The EconomicJournal, v. 92, n. 368, p. 825-848, 1982

CRUZ, J. L.; TERRA, D. C. T. Indústria extrativa petrolífera fluminense e limites ao desenvolvimento regional. Terceiro Milêncio: Revista Crítica de Sociologia e Política, v. 4, n. 4, n. 1, p. 31-44, 2015

DANTAS, A.; KERSTENETZKY, J.; PROCHNIK, V. Empresa, indústria e mercados. In KUPFER, D.; HASENCLEVER, L. (Orgs.) Economia industrial: fundamentos teóricos e práticas no Brasil.2a. ed. Rio de Janeiro: Elsevier. 2013, p. 15-24.

DI JOHN, J. Is there really a resource curse? A critical survey of theory and evidence. Global Governance, v. 17, n. 2, p. 167-184, 2011.

FERREIRA, M. L. A. Formação e capacitação em engenharia no setor de petróleo: a cooperação entre ANP, Petrobras e universidades do estado do Rio de Janeiro. Tese (Doutorado em Políticas Públicas, Estratégias e Desenvolvimento). Instituto de Economia, Universidade Federal do Rio de Janeiro (IE/UFRJ), Rio de Janeiro, RJ, 2015.

FRANKEL, J. A. The natural resource curse: a survey. [Working Paper $\mathrm{n}^{\circ} 15.836$ ]. National Bureau of Economic Research (NBE). Massachusetts: United States, 2010. 
FRANKEL, J. A. The natural resource curse: a survey of diagnoses and some prescriptions. [HKS Faculty Research Working Paper Series RW12-014]. John F. Kennedy School of Government, Harvard University. Massachusetts: United States, 2012.

FRISCHTAK, C. R.; BELLUZZO, L. G. M. Produção de commodities e desenvolvimento econômico: uma introdução. In: BELLUZZO, L. G. M.; FRISCHTAK, C. R. \& LAPLANE, M. (Orgs.). Produção de commodities e desenvolvimento econômico. Campinas: UNICAMP, Instituto de Economia, 2014, p. 9-20.

FURTADO, C. Formação de capital e desenvolvimento econômico.Revista Brasileira de Economia, v. 6, n. 3, p. 7-45, 1952.

FURTADO, C. Desenvolvimento e subdesenvolvimento. Rio de Janeiro: Fundo de Cultura, 1961.

GIL, A. C. Métodos e técnicas de pesquisa social. 7 ed. São Paulo: Atlas, 2021.

GOBETTI, S. W.; ORAIR, R. O.; SERRA, R. V.; SILVEIRA, F. G. A polêmica mudança na partilha das receitas petrolíferas. [Texto para Discussão $n$. 2566]. Rio de Janeiro: IPEA, 2020.

HIRSCHMAN, A. O. Estratégia do desenvolvimento econômico. Rio de Janeiro: Fundo de Cultura, 1961.

KALDOR, N. Causes of the slow rate of economic growth of the United Kingdom: an inaugural lecture. London: Cambridge University Press, 1966.

KALDOR, N. Further essays on economic theory, New York: Holmes \& Meier, 1978.

LENCIONI, S. Condições gerais de produção. In. SPOSITO, E. S. (Org.). Glossário de Geografia Humana e Econômica. São Paulo: Unesp, 2017, p. 73-78.

LIMA, A. C. C.; SIMÕES, R. F. Teorias clássicas do desenvolvimento regional e suas implicações de política econômica: o caso do Brasil. Revista de Desenvolvimento Econômico, Ano XII, n. 21, p. 5-19, 2010.

LUMBRERAS, M. J.; PIQUET, R. Riqueza movida a petróleo: maldição ou alavanca para o desenvolvimento? Novos Cadernos NAEA, v. 23, n. 1, p. 59-80, 2020.

MACIEL, G. C. A. Recursos naturais e desenvolvimento econômico: bênção, maldição ou oportunidade? Tese (Doutorado em Economia). Instituto de Economia, Universidade Federal do Rio de Janeiro (IE/UFRJ), Rio de Janeiro, RJ, 2015. 
MADUREIRA, E. M. P. Desenvolvimento regional: principais teorias. Revista Thêma et Scientia, v. 5, n. 2, p. 8-23, 2015.

MARCELLINO, I. S. Políticas Regionais de Inovação em um cenário institucional fragmentado: o complexo produtivo de petróleo e gás natural no contexto do Sistema Regional de Inovação do Rio de Janeiro. Revista Pymes, Innovación y Desarrollo, v. 4, n. 1, p. 37-56, 2016.

MARCELLINO, I. S.; VEIGA, L.; RABELO, H.; FALCÃO, M. O potencial representado pelo Sistema Produtivo de Petróleo e Gás no Rio de Janeiro e implicações para o desenvolvimento regional. [Nota Técnica 01]. Alerj, Rio de Janeiro, RJ, Brasil, 2020.

MARCONI, M. A.; LAKATOS, E. M. Metodologia do trabalho científico: procedimentos básicos, pesquisa bibliográfica, projeto e relatório, publicações e trabalhos científicos. 7 . ed. São Paulo: Atlas, 2012.

MADUREIRA, E. M. P. Desenvolvimento regional: principais teorias. Revista Thêma et Scientia, v. 5, n. 2, p. 8-23, 2015.

MENDES, H. S.; FERREIRA, M. L. A.; CAVALIERI, H. Protagonismo do Estado do Rio de Janeiro na exploração e produção de petróleo e gás natural: até quando? Boletim Petróleo, Royalties e Região, Ano XV, n. 57, p. 3-7, 2017.

OBSERVATÓRIO DOS BENEFÍCIOS FISCAIS.Jogando luz na escuridão. [Relatório]. Secretaria de Estado de Fazenda do Rio de Janeiro, Rio de Janeiro, RJ, Brasil, 2016.

OLIVEIRA, A. Petróleo no Rio de Janeiro: trocar a maldição pelo desenvolvimento. Jornal dos Economistas, n. 379, p. 5-6, 2021.

OLIVEIRA, M. F. D. Manufatura 4.0: a indústria do petróleo e a transformação digital Dissertação (Mestrado em Engenharia de Produção). Escola de Engenharia, Universidade Federal Fluminense (UFF), Niterói, RJ, 2019.

OLIVEIRA, A.; MELO, H. P. O papel do setor petrolífero no desenvolvimento fluminense. In: OSORIO, M.; MELO, L. M.; VERSIANI, M. H. \& WERNECK, M. L. (Orgs.). Uma agenda para o Rio de Janeiro: estratégicas e políticas públicas para o desenvolvimento sócio-econômico. Rio de Janeiro: FGV Editora, 2015, p. 45-66.

PAMPLONA, J. B.; CACCIAMALI, M. C. A maldição dos recursos naturais: atualizando, organizando e interpretando o debate. Economia e Sociedade, v. 27, n. 1, p. 129-159, 2018.

PÉREZ, C. Dinamismo tecnológico e inclusión social en América Latina: una estrategia de desarrolloproductivobasadaenlos recursos naturales. Revista Cepal, v. 100, n. 2, p. 123-145, 2010 . 
PÉREZ, C.; MARÍN, A.; NAVAS-ALEMÁN, L. El posible rol dinámico de las redes basadasen recursos naturales para lasestrategias de desarrolloen América Latina. In: DUTRÉNIT, G.; SUTZ, J. (Orgs.). Sistemas de innovación para undesarrollo inclusivo: laexperiencia latino-americana. México: Foro Consultivo, Científico y Tecnológico, 2013. p. 347-377.

PLOEG, F. van der. Natural resources: curse or blessing? Journal of Economic Literature, v. 49, n. 2, p. 366-420, 2011.

PREBISCH, R. O desenvolvimento econômico da América Latina e seus principais problemas. Revista Brasileira de Economia, v. 3, n. 3, p. 47-111, 1949.

RIBEIRO, E. M. F. Exportações de petróleo e a maldição dos recursos naturais: um estudo empírico para o Brasil. Dissertação (Mestrado em Economia e Relações Internacionais). Universidade Federal de Uberlândia (UFU), Uberlândia, MG, 2019.

RIBEIRO, A. C.; HASENCLEVER, L. Investigação sobre a capacidade de absorção de externalidades positivas geradas por grandes projetos no estado do Rio de Janeiro. RevistaEconômica do Nordeste, v. 50, n. 2, p. 133-145, 2019.

SACHS, J. D.; WARNER, A. M. Natural resource abundance and economic growth. [Working Paper $n^{\circ}$ 5.398]. National Bureau of Economic Research (NBE). Massachusetts: United States, 1995.

SACHS, J. D.; WARNER, A. M. Fundamental sources of long-run growth. The American Economic Review v. 87, n. 2, p. 184-188; 1997.

SACHS, J.; WARNER, A. The curse of natural resources. European Economic Review, v. 45, n. 4-6, p. 827-838, 2001.

SANTOS, G. O. Caminhos para a construção de uma nova estratégia de desenvolvimento: uma abordagem evolucionária do sistema regional de inovação do estado do Rio de Janeiro. Tese (Doutorado em Políticas Públicas, Estratégias e Desenvolvimento). Instituto de Economia, Universidade Federal do Rio de Janeiro (UFRJ), Rio de Janeiro, RJ, 2020.

SILVA, E. M. G. Cadeias produtivas e complexos industriais da economia fluminense. Dissertação (Mestrado em Economia). Centro de Desenvolvimento e Planejamento Regional, UFMG (CEDEPLAR/UFMG), Belo Horizonte, MG. 2007.

SILVA, R. D.; MATOS, M. V. M. Petróleo e desenvolvimento regional: o Rio de Janeiro no pós-boom das commodities. Revista de DesenvolvimentoEconômico, v. 2, n. 34, p. 704-722, 2016.

SINGER, H. W. The distribution of gains between investing and borrowing countries. The American EconomicReview, v. 40, n. 2, p. 473-485, 1950. 
SOBRAL, B. L. B.A falácia da "inflexão econômica positiva": algumas características da desindustrialização fluminense e do "vazio produtivo" em sua periferia metropolitana. Cadernos do Desenvolvimento Fluminense, n. 1, p. 53-85, 2013.

VERÍSSIMO, M. P. Exportações de petróleo e a hipótese da Maldição dos Recursos Naturais no Brasil. Revista Brasileira de Inovação, v. 18, n. 1, p. 63-88, 2019.

VIEIRA, D. J. Um estudo sobre a guerra fiscal no Brasil. Tese (Doutorado em Desenvolvimento Econômico), Instituto de Economia, Universidade Estadual de Campinas (IE/Unicamp), Campinas, SP, 2012.

YERGIN, D. O petróleo: uma história mundial de conquistas, poder e dinheiro. São Paulo:

Paz

e

Terra,

2010. 